\title{
Geography \& Entrepreneurship: Managing Growth and Change
}

\author{
João J. Ferreira ${ }^{1} \cdot$ Elias G. Carayannis $^{2}$ • \\ David F.J. Campbell ${ }^{3,4}$ • Luís Farinha ${ }^{5}$. \\ Helen Lawton Smith ${ }^{6,7}$ • Sharmistha Bagchi-Sen ${ }^{8}$
}

Received: 3 November 2017 / Accepted: 14 November 2017

(C) Springer Science+Business Media, LLC, part of Springer Nature 2017

\begin{abstract}
This introduction to the special issue "Geography \& Entrepreneurship: Managing Growth and Change" in the Journal of The Knowledge Economy includes a collection of seven papers. Through theoretical and empirical research, this special
\end{abstract}

João J. Ferreira

jjmf@ubi.pt

Elias G. Carayannis

caraye@email.gwu.edu

David F.J. Campbell

David.Campbell@aau.at

Luís Farinha

luis.farinha@ipcb.pt

Helen Lawton Smith

ubtm188@mail.bbk.ac.uk

Sharmistha Bagchi-Sen

geosbs@buffalo.edu

1 University of Beira Interior \& NECE—-Research Unit, Covilhã, Portugal

2 George Washington University, Washington, DC, USA

3 Alpen-Adria-University Klagenfurt, Wien, Austria

4 University of Applied Arts Vienna, am Wörthersee, Klagenfurt, Austria

5 Polythecnic Institute of Castelo Branco \& NECE — Research Unit, University of Beira Interior, Covilhã, Portugal

6 Birkbeck, University of London, London, UK

7 Oxfordshire Economic Observatory, Oxford University, Oxford, UK

8 State University of New York - Buffalo, Buffalo, NY, USA 
issue aims to clarify the connection between geography and entrepreneurship. In doing so, growth strategies and change trajectories of countries, regions, and firms are analyzed. The papers use extensive data that enable the models to provide a rich picture of how academic institutions, companies, and regional governments contribute to regional development. As a result, these studies provide new perspectives on regional entrepreneurial transformation. Theoretical perspectives, methodologies, and their application to several contexts provide an advancement of our understanding about Geography and Entrepreneurship. Perspectives on R\&D and knowledge, internationalization strategies, high-growth businesses, technological entrepreneurs, university spin-offs, transnational entrepreneurship, and entrepreneurial networks are dominant themes included in this special issue. A brief description of the authors' contributions is offered to attract a broader readership.

Keywords Entrepreneurship - Geography · Managing growth $\cdot$ Knowledge $\cdot$ Change

\section{Theoretical Background}

The claim that differences in national and regional socio-economic development are related to the presence or lack of an entrepreneurial culture is not new, and is transversal to different schools of thought (Huggins and Williams 2011; Backman and Lööf 2015). In recent decades, a wide group of authors has revealed a strong association between entrepreneurship and the progress of economic geographies (Acs and Amorós 2015; Lawton Smith et al. 2005). Regarding territorial growth, we can take a regional perspective (place, locality, city, urban area, island or archipelago, or territorial space) or a national vision (country) focusing on a number of countries (e.g., set of countries in accordance with their common official language or geographical location, and economic status) or an international perspective. Examples include Latin America, the PALOP countries the Baltic States, the BRIC economies-Brazil, Russia, India, China, etc. (Camagni and Capello 2013).

In a territorial cooperation perspective, the Triple Helix model, developed by Leydesdorff and Etzkowitz (1996), focuses on the university-industry-government interactions (Etzkowitz et al. 2005; Farinha et al. 2016) while the Quadruple adds civil society (the media- and culture-driven public) as a fourth helix (Leydesdorff 2012). The Quintuple Helix innovation model is a framework for facilitating knowledge, innovation, and sustainable competitive advantage. It embeds the Triple and the Quadruple Helix models by adding a fifth helix, the "natural environment" (Carayannis et al. 2012).

In each of these stages of institutional cooperation, and in a perspective of collaborative economic geography, in its triangulation model of the triple helix, Farinha and Ferreira (2012) reinforce the importance of the role of innovation and entrepreneurship in the context of regional development (Farinha et al. 2016; Lawton Smith and Bagchi-Sen 2012). During the last decades, the topic of entrepreneurship has received increased academic attention all over world. The economic geography of entrepreneurship is today a lively area of debate for example on such topics as the importance of the exploitation of endogenous potential of the territories versus extra- 
local influences, geographies of collaborative networks, and the functioning as knowledge and technology spillovers (Backman and Lööf 2015).

According to the literature review, we seek answers to the following research questions, given that there is still a gap not sufficiently explained: (1) Why do some countries or some regions grow more than others? (2) What is impact of opportunity and necessity-based entrepreneurship in their socio-economic progress? (3) What is the impact of networks of cooperation and business, and ecosystems of entrepreneurship and innovation for the competitiveness of geographies? (4) Does local policy matter?

From the perspective of growth and change management, Mason and Brown (2014) argue that the definition of the growth-oriented entrepreneurship policy should focus on the following: (1) Collaborative networks and sectoral clusters, (2) Groups of entrepreneurs and entrepreneurial projects with high potential for success, (3) Connecting components within ecosystems, developing connections between entrepreneurial actors, institutional alignment of priorities, fostering peer-based interactions, (4) Recognition that different businesses have different funding requirements such as debt finance and crowdfunding, and (5) Open innovation systems, transversal to different sectors and industries.

The centrality of the EU's Smart Specialization Strategies (i.e., smart use of regional resources) is now in the political agendas of countries and regions (Ács et al. 2014; Miguélez and Moreno 2015; Vendrell-Herrero and Wilson 2017). In this alignment, the dynamics of the Quadruple Helix, Innovation, entrepreneurship, and the KnowledgeBased Development can add an important contribution to the development of Remote, Rural, and Less-Favored Regions (Kolehmainen et al. 2016).

For instance, the literature reveals that the geography and entrepreneurship should be studied together in order to allow the definition of territorial growth strategies at local, regional, and global levels. The emergence of new business models based on innovation, cooperation networks, and the enhancement of endogenous resources are assumed to be a strong contribution to the development of competitive economies and regions, especially for low density and peripheral territories.

This Special Issue aims to address the effects of these organizational, entrepreneurial, and institutional advances and their impact on regional competitiveness for sustainable, smart, and equitable economic growth.

\section{Contents of this Special Issue}

The seven papers in this special issue cover a series of inter-related topics.

The first entitled "Science policy, R\&D and knowledge in Portugal: an application of social network analysis," by Rui Gama, Cristina Barros, and Ricardo Fernandes, analyzes networks of scientific and technological collaboration of the territories where the main public universities in Portugal are located. According to these authors, this analysis establishes an excellent indicator for delineating public policies and encourages the creation of new networks. Furthermore, the paper shows that universities are assets that promote the processes of innovation, which is a determining factor for the development and growth of the territories' competitive capability.

The second explores the effects of knowledge, cooperation, and innovation on internationalization strategy. The paper entitled "Internationalization Strategy of 
Knowledge-Intensive Business Services,” by Alexandra Braga, Carla Marques, and Zélia Serrasqueiro, shows that knowledge personaliation has a positive influence on proactive strategies of internationalization, such as innovation and new organization methods. This research contributes to reinforce the need for adjustment of public policies to encourage the development and strengthening of proactivity in this sector with regard to internationalization and formal/informal network formation.

The third explores the entrepreneurial initiatives needed to create or manage highgrowth business, with a special emphasis on cross-country perceptions of such economic activity. The paper entitled "High-growth business creation and management: A multivariate quantitative approach using GEM data," authored by Vitor Braga, Maria Queirós, Aldina Correia, and Alexandra Braga, focuses on GEM database and they suggest that individuals who react quickly to opportunities seem to display better abilities of time management and are more willing to start a business.

The fourth identifies the profiles of Brazilian technological entrepreneurs regarding their motivation to start a technological business. The paper entitled "Types of technological entrepreneurs: a study in a large emerging economy," by Sarah Lasso, Emerson Mainardes, and Fabio Yoshio Motoki, argues that different motivations of different groups can generate more effective, directed policies allowing adequate levels of entrepreneurial activity and maximizing the benefits of entrepreneurship. Discussion about policy design to support entrepreneurship is raised.

The fifth focuses on contribution of University Spin-Offs for regional competitiveness. This is important given that the commercialization and diffusion of knowledge/ technology, developed in academia, have increased the attention of policymakers as strategic and key to fostering regional socio-economic development and competitiveness. This paper entitled "The contribution of University Spin-Offs to the competitive advantage of regions" is authored by Christian Corsi and Antonio Prencipe. Regarding the theoretical implications, this paper contributes to our knowledge about the role of technology transfer mechanisms from university in improving the socio-economic competiveness of regions.

The sixth advances the common domain of knowledge spillovers (KS) and strategic entrepreneurship by pinpointing further links between these two fields and by providing a series of real-world examples of how KS can be strategically applied for the longterm gain of all parties involved in the KS process. The paper entitled "Transnational Entrepreneurship as a Win-Win Scenario of International Knowledge Spillover," authored by Vanda Veréb and João Ferreira, shows how international KS can be beneficial for both the incumbent and recipient economies. According to the authors, this benefit is derived from the mobile and multiple-embedded nature of transnational entrepreneurs and realized through providing economic, cultural, social and institutional assets to both countries.

Finally, the seventh proposes a performance measurement model for innovation and entrepreneurial networks. The paper entitled "Metrics for innovation and entrepreneurial networks," authored by João Lopes and Luis Farinha, shows through a systematic literature review the need to identify measures to analyze the impact of the multiple helix ecosystem for sustainable competiveness. A balanced scoreboard application and a strategic map are suggested as a potential tools. 


\section{Conclusion and Future Agenda}

Generally, the papers in this issue contribute to a better understanding of the complex topic of geography and entrepreneurship. A broad range of thematic analysis underlying Geography and Entrepreneurship are developed and explored in this special issue. These studies suggest several important aspects for future agenda and they can be summarized in these five topics:

i) Understanding the role of universities in the process of the production of knowledge, the structure, the specialization and competences of the resources, and territorial specialization within the scope of public policy affecting to science and technology remain open;

ii) The need for adjustment of public policies to encourage the development and strengthening of proactivity of the knowledge-intensive business sector with regard to internationalization and formal and informal networks;

iii) Explorations of which countries the experts underrate their country entrepreneurs' abilities to create and manage high-growth businesses and which ones overrate such skills seems important to analyze. High-growth businesses are a relevant phenomenon for economies as they represent an important driver for economic growth;

iv) Analysis of the impact of University Spin-Offs (USO) on regional competitiveness by distinguishing among direct and indirect impact in order to obtain additional insights about the composition and dissimilarities in the effects of USOs' activity and outcome;

v) Refining the theory and stimulating further research on domain of international business and transnational entrepreneurship;

vi) Critiquing the assumption that regional development networks are fundamental to fostering entrepreneurship and innovation in a region's competitiveness. The relative roles that universities, industry, government, and society play in regional networks should be analyzed.

We hope that this special issue will lead the way for more research about this theme particularly from a multidisciplinary perspective. There are several challenges not covered here and they deserve future attention.

Acknowledgements A sincere word of thanks goes to our team of reviewers for their collaboration and valuable comments. Without their support it would not have been possible to produce this special issue.

As Guest Editors, we profoundly appreciate the support received from Elias G. Carayannis, the editor-inchief of the Journal of the Knowledge Economy.

\section{References}

Acs, Z., \& Amorós, J. (2015). Entrepreneurship and development: the role of clusters. Small Business Economics, 39(3), 561-574. https://doi.org/10.1007/s11187-015-9643-3. 
Ács, Z. J., Szerb, L., Ortega-Argilés, R., AIdis, R., \& Coduras, A. (2014). The regional application of the global entrepreneurship and development index (GEDI): the case of Spain. Regional Studies, 3404(December), 1-18. https://doi.org/10.1080/00343404.2014.888712.

Backman, M., \& Lööf, H. (2015). The geography of innovation and entrepreneurship. The Annals of Regional Science, 55(1), 1-6. https://doi.org/10.1007/s00168-015-0713-x.

Camagni, R., \& Capello, R. (2013). Regional competitiveness and territorial capital: a conceptual approach and empirical evidence from the European Union. Regional Studies, 47(9), 1383-1402. https://doi. org/10.1080/00343404.2012.681640.

Carayannis, E. G., Barth, T. D., \& Campbell, D. F. (2012). The Quintuple Helix innovation model: global warming as a challenge and driver for innovation. Journal of Innovation and Entrepreneurship, 1(1), 2. https://doi.org/10.1186/2192-5372-1-2.

Etzkowitz, H., de Mello, J. M. C., \& Almeida, M. (2005). Towards “meta-innovation" in Brazil: the evolution of the incubator and the emergence of a triple helix. Research Policy, 34(4), 411-424. https://doi. org/10.1016/j.respol.2005.01.011.

Farinha, L., \& Ferreira, J. J. (2012). Triangulation of the Triple Helix: A conceptual framework for regional competitiveness focused on innovation and local entrepreneurship. In THA (Ed.), The 10th Triple Helix International Conference (pp. 487-501). Penerbit ITB: Bandung.

Farinha, L., Ferreira, J., \& Gouveia, B. (2016). Networks of innovation and competitiveness: a triple helix case study. Journal of the Knowledge Economy, 7(1), 259-275. https://doi.org/10.1007/s13132-014-0218-3.

Huggins, R., \& Williams, N. (2011). Entrepreneurship and regional competitiveness: the role and progression of policy. Entrepreneurship \& Regional Development, 23(9-10), 907-932. https://doi.org/10.1080 /08985626.2011.577818.

Kolehmainen, J., Irvine, J., Stewart, L., Karacsonyi, Z., Szabó, T., Alarinta, J., \& Norberg, A. (2016). Quadruple helix, innovation and the knowledge-based development: lessons from remote, rural and less-favoured regions. Journal of the Knowledge Economy, 7(1), 23-42. https://doi.org/10.1007 /s13132-015-0289-9.

Lawton Smith, H., \& Bagchi-Sen, S. (2012). The research university, entrepreneurship and regional development: research propositions and current evidence. Entrepreneurship \& Regional Development, 24(5-6), 383-404. https://doi.org/10.1080/08985626.2011.592547.

Lawton Smith, H., Glasson, J., \& Chadwick, A. (2005). The geography of talent: entrepreneurship and local economic development in Oxfordshire. Entrepreneurship \& Regional Development, 17(6), 449-478. https://doi.org/10.1080/08985620500247819.

Leydesdorff, L. (2012). The triple helix, quadruple helix, ..., and an N-tuple of helices: explanatory models for analyzing the knowledge-based economy? Journal of the Knowledge Economy, 3(1), 25-35. https://doi. org/10.1007/s13132-011-0049-4.

Leydesdorff, L., \& Etzkowitz. (1996). Emergence of a Triple Helix of university-industry-government relations. Science and Public Policy, 23(1), 279-286.

Mason, Colin; Brown, R. (2014). Entrepreneurial ecosystems and growth oriented entrepreneurship. Oecd, 138.https://doi.org/10.1007/s13398-014-0173-7.2

Miguélez, E., \& Moreno, R. (2015). Knowledge flows and the absorptive capacity of regions. Research Policy, 44(4), 833-848. https://doi.org/10.1016/j.respol.2015.01.016.

Vendrell-Herrero, F., \& Wilson, J. R. (2017). Servitization for territorial competitiveness: taxonomy and research agenda. Competitiveness Review, 27(1), 2-11. 